\title{
Differential Regulation of cGMP Signaling in Human Melanoma Cells at Altered Gravity: Simulated Microgravity Down-Regulates Cancer-Related Gene Expression and Motility
}

\author{
Krassimira Ivanova $^{1} \cdot$ Peter Eiermann ${ }^{1} \cdot$ Wasiliki Tsiockas $^{1} \cdot$ Ruth Hemmersbach $^{1} \cdot$ Rupert Gerzer $^{2}$
}

Received: 10 September 2017 / Accepted: 21 March 2018 / Published online: 29 March 2018

(C) The Author(s) 2018

\begin{abstract}
Altered gravity is known to affect cellular function by changes in gene expression and cellular signaling. The intracellular signaling molecule cyclic guanosine-3', $5^{\prime}$-monophosphate (cGMP), a product of guanylyl cyclases (GC), e.g., the nitric oxide (NO)-sensitive soluble GC ( $\mathrm{sGC}$ ) or natriuretic peptide-activated GC (GC-A/GC-B), is involved in melanocyte response to environmental stress. NO-sGC-cGMP signaling is operational in human melanocytes and non-metastatic melanoma cells, whereas up-regulated expression of GC-A/GC-B and inducible NO synthase (iNOS) are found in metastatic melanoma cells, the deadliest skin cancer. Here, we investigated the effects of altered gravity on the mRNA expression of NOS isoforms, sGC, GC-A/GC-B and multidrug resistance-associated proteins 4/5 (MRP4/MRP5) as selective cGMP exporters in human melanoma cells with different metastatic potential and pigmentation. A specific centrifuge (DLR, Cologne Germany) was used to generate hypergravity $(5 \mathrm{~g}$ for $24 \mathrm{~h}$ ) and a fast-rotating 2-D clinostat (60 rpm) to simulate microgravity values $\leq 0.012 \mathrm{~g}$ for $24 \mathrm{~h}$. The results demonstrate that hypergravity up-regulates the endothelial NOS-sGCMRP4/MRP5 pathway in non-metastatic melanoma cells, but down-regulates it in simulated microgravity when compared to $1 \mathrm{~g}$. Additionally, the suppression of sGC expression and activity has been suggested to correlate inversely to tumor aggressiveness. Finally, hypergravity is ineffective in highly metastatic melanoma cells, whereas simulated microgravity down-regulates predominantly the expression of the cancer-related genes iNOS and GC-A/GC-B (shown additionally on protein levels) as well as motility in comparison to $1 \mathrm{~g}$. The results suggest that future studies in real microgravity can benefit from considering GC-cGMP signaling as possible factor for melanocyte transformation.
\end{abstract}

Keywords Guanylyl cyclase-cGMP signaling $\cdot$ Human melanoma cells $\cdot$ Hypergravity $\cdot$ Simulated microgravity 2-D clinostat

\section{Introduction}

Gravity (g) alterations are known to affect gene expression and cellular functions. Both, the condition of microgravity that means without the impact of the gravitational stimulus as well as hypergravity, which means increase of the gravitational stimulus to a moderate physiological level, have been proven as tools to elucidate the effects of gravity on

Krassimira Ivanova

krassimira.ivanova@dlr.de

1 Institute of Aerospace Medicine, German Aerospace Center (DLR), Linder Hoehe, 51147 Cologne, Germany

2 Skolkovo Institute of Science and Technology, 3 Nobel Street, 143026 Moscow, Russia cellular response (Aleshcheva et al. 2016; Brungs et al. 2016; Hughes-Fulford and Lewis 1996; Hughes-Fulford 2003; Ivanova et al. 2004, 2011; Ulbrich et al. 2011; Thiel et al. 2012). To our knowledge, studies concerning the influence of gravity on human melanocytes and melanoma cells in respect to activation and cellular responses that are important for malignant transformation have been rarely reported. As specialized skin cells, human epidermal melanocytes provide protection against harmful ultraviolet (UV) radiation and oxidative stress by generating the radical scavenging pigment melanin. Melanocytes are also precursor cells of melanoma, the deadliest skin cancer. Although exposure to UV radiation (UVA and UVB) is a major risk factor for melanoma development, it can also arise on not UV-exposed skin, depending on inflammation and immune status (Merkel and Gerami 2017; Sample and He 
2017). In addition, space flight induces a reduction in the immune competence among crew, leading to increased risk of infection and altered antibiotic susceptibility (Ullrich et al. 2008; Taylor 2015; Frippiat et al. 2016). Interestingly, reduced cyclic guanosine- $3^{\prime}, 5^{\prime}$-monophosphate (cGMP or cyclic GMP) levels in human plasma were found in astronauts after long-term space flight (Rossler et al. 2001).

Cyclic GMP is an intracellular signaling molecule that regulates essential (patho)physiologigal processes in multiple cell types including tumor cells, such as smooth muscle relaxation, platelet aggregation, neurotransmission, cell growth and survival (Lucas et al. 2000; Beavo and Brunton 2002; Bian et al. 2012; Fajardo et al. 2014). It can be generated from GTP by two classes of guanylyl cyclases (GC), the nitric oxide (NO)-sensitive soluble GC (sGC) (Derbyshire and Marletta 2012) or the peptide-activated membrane-bound $\mathrm{GC}$, such as the atrial natriuretic peptide (ANP)-responsive GC-A or the C-type natriuretic peptide (CNP)-responsible GC-B (Potter et al. 2006). The sGC occurs as a heme-containing heterodimeric protein consisting of $\alpha$ and $\beta$ subunits (Gerzer et al. 1981; Ignarro 1990). The $\alpha_{1} \beta_{1}$ heterodimer is the predominant sGC isoform that is required for catalytic activity (Zhao et al. 1998). Cyclic GMP exerts its effects by targeting downstream effectors such as cGMP-dependent protein kinases (PKG), cGMP-regulated phosphodiesterases (PDE), cyclic nucleotide-gated channels, and the multidrug resistanceassociated proteins 4 (MRP4) and 5 (MRP5) as selective cGMP exporters (Wielinga et al. 2003; Hofmann 2005; Conti and Beavo 2007; Biel and Michalakis 2009). In addition, whereas MRP5 has much higher affinity to export cGMP than MRP4 (Sager 2004; Jedlitschky et al. 2000; Wielinga et al. 2003), both MRP4 and MRP5 also export nucleoside analogs that are used in antiviral and anticancer therapy (Deeley et al. 2006).

For melanocytes, the NO-sGC-cGMP-PKG signaling pathway is involved in UV-B-dependent melanogenesis (Romero-Graillet et al. 1996) as well as in NO-induced detachment from extracellular matrix components like fibronectin (Ivanova et al. 1997, 2005). Importantly, the NO-sGC-cGMP signaling in association with pigmentation is operational in human melanocytes and non-metastatic melanoma cells and not in highly metastatic phenotype (Ivanova et al. 2001, 2008). On the contrary, expression and activities of the ANP-responsible GC-A and CNPresponsible GC-B in human metastatic melanoma cells were related to their metastatic potential (Ivanova et al. 2001, 2008). Further, it was shown that GC-A attenuation or deficiency protects mice from tumorigenesis in lung and ovarian cancer as well as in melanomas, possibly because GC-A positive cells in the tumor stroma are involved in the regulation of local inflammation and tumor angiogenesis (Kong et al. 2008). It has also been reported that CNP promotes melanoma cell growth and migration via activation of the GC-B-cGMP-PKGI pathway (Dhayade et al. 2016). In addition, expression of the inducible NOS (iNOS) predicts poor survival for stage III melanoma patients and low levels of NO production by constitutive iNOS expression seem to play a role in the melanoma resistance to apoptosis (Ekmekcioglu et al. 2006; Grimm et al. 2008).

Finally, the cGMP signaling is also involved in melanocyte response to gravity alterations. Hypergravity (up to $5 \mathrm{~g}$ for $24 \mathrm{~h}$ ) stimulated cGMP efflux in cultured human melanocytes and non-metastatic melanoma cell lines and not in metastatic phenotypes under conditions of limited PDE activities or increased sGC activity via stimulation by NO, whereas simulated microgravity $(\leq 0.012 \mathrm{~g}$ for $24 \mathrm{~h})$ down-regulated the expression of the natriuretic peptideresponsible GC-A and GC-B in human melanoma cells (Ivanova et al. 2004, 2011; Stieber et al. 2005).

In the present study, we focused on the effects of altered gravity on the expression of GC-cGMP signaling components (e.g., iNOS/eNOS, sGC, GC-A/GC-B, PKGI, PDE5, MRP4/MRP5, and tyrosinase-TYR as a key enzyme in melanogenesis) in melanoma cell lines with different metastatic potential and pigmentation. A specific centrifuge (STATEX II, DLR, Cologne Germany) that allows defined acceleration changes (Neubert et al. 1996) was used to generate hypergravity in a physiological range and a fast rotating 2-D clinostat with a horizontal axis of rotation (Briegleb 1992) to simulate microgravity conditions (Herranz et al. 2013). Our study demonstrates that simulated microgravity down-regulates the expression cancer-related cGMP-signaling components as well as motility in highly metastatic melanoma cells.

\section{Materials and Methods}

\section{Cell Culture and Transfection Procedure}

The human melanoma cell lines used in this study were a kind gift from Prof. Dr. G. van Muijen, Department of Pathology, Nijmegen University, The Netherlands. Pigmented 1F6 -non-metastatic (Danen et al. 1993) to low metastatic (Le Poole et al. 1997) and highly metastatic and non-pigmented BLM melanoma cells (Van Muijen et al. 1991; Danen et al. 1993) were grown in Dulbecco's modified Eagle's medium (DMEM), supplemented with $10 \%$ (v/v) heat-inactivated fetal calf serum (FCS), $2 \mathrm{mM}$ glutamine, and antibiotics (all from Invitrogen, Thermo Fisher Scientific GmbH, Langenselbold, Germany) as described elsewhere (Ivanova et al. 1997).

The 1F6 melanoma cell line (functional sGC expression) was transfected with siRNA for sGC- $\beta_{1}$ subunits using the 
ON-TARGETplus ${ }^{\mathrm{TM}}$ SMARTpool siRNA reagents (Fischer Scientific Dharmacon, Langesebold, Germany) according to the manufacture's protocol. Briefly, the melanoma cells were seeded at a density of $0.2 \times 10^{6}$ cells per $12.5 \mathrm{~cm}^{2}$ flasks or $0.10 \times 10^{6}$ cells per $9 \mathrm{~cm}^{2}$ slide flasks and were then cultivated for $24 \mathrm{~h}$ in antibiotic-free complete DMEM medium at $37{ }^{\circ} \mathrm{C}, 5 \% \mathrm{CO}_{2}$. After washing with phosphate buffered saline (PBS), the cells were transfected with 100 nM siRNA-sGC $\beta_{1}$ (SMARTpool I, J006733050020, UCAUGAACCUGGACGAUUU), $50 \mathrm{nM}$ siRNA-PPIB (positive control) (D00182010), $50 \mathrm{nM}$ non-targeting or scrambled siRNA as negative control (SMARTpool I, D0018100120), and $6 \mu \mathrm{l}$ DharmaFECT 1 transfection reagent (T200103) (all from Abgene Ltd., Cambridge, $\mathrm{UK}$ ) in $2 \mathrm{ml}$ DMEM medium supplemented with $0.2 \%$ FCS. The target mRNA knockdown was assayed after $24 \mathrm{~h}$ of transfection. The inhibition with siRNA-sGC- $\beta_{1}$ was measured by both quantitative real-time polymerase chain reaction (qPCR) and Western blot analyzes.

\section{Experimental Design}

For exposure to altered gravity conditions, human melanoma cells were seeded at a density of $0.2 \times 10^{6} / 0.4 \times 10^{6}(\mathrm{BLM})$ or $0.4 \times 10^{6} / 0.8 \times 10^{6}(1 \mathrm{~F} 6)$ cells per $12.5 \mathrm{~cm}^{2} / 24 \mathrm{~cm}^{2}$ culture flasks (Falcon, Becton \& Dickinson, Heidelberg, Germany) for hypergravity and of $0.1 \times 10^{6}$ (BLM) or $0.2 \times 10^{6}$ (1F6) cells per $9 \mathrm{~cm}^{2}$ slide flasks (Nunc, Thermo Fisher Scientific, Langenselbold, Germany) for simulated microgravity experiments, respectively. Cells were then grown for $24 \mathrm{~h}$ at $37^{\circ} \mathrm{C}$ and $5 \% \mathrm{CO}_{2}$ in DMEM, containing $10 \%$ FCS and antibiotics. After washing with PBS, the cells were maintained for $3 \mathrm{~h}$ at $37{ }^{\circ} \mathrm{C}$ and $5 \% \mathrm{CO}_{2}$ in culture flasks completely filled with mitogen-deficient medium, containing phenol-red free DMEM medium supplemented with $0.25 \%$ bovine serum albumin (BSA), $10 \mathrm{mM}$ HEPES (4-(2-hydroxyethyl)-1-piperazine-ethanesulphonic acid), pH 7.4 (DMEM-HEPES) (Sigma-Aldrich Chemie GmbH, Munich, Germany) and 0.1 mM 3-isobutyl-1methylxanthine (IBMX) (Sigma-Aldrich Chemie $\mathrm{GmbH}$, Munich, Germany) as a non-selective PDE inhibitor. Finally, the different experiments were performed only with cells from the same passage number. Cell viability was assessed by trypan blue exclusion assay and cell morphology was monitored by light microscopy.

Hypergravity was produced by centrifugation with a STATEX II centrifuge from the Spacelab mission D2 (DLR, Cologne, Germany) (Neubert et al. 1996) modified for studies with cell cultures as described previously (Ivanova et al. 2004). Briefly, the flasks positions were adjusted to be perpendicular to the acceleration vector that is the resultant vector of both the centrifugal vector and the normal (Earth's) gravity vector. Constant hypergravity levels (up to $10 \mathrm{~g}$ ) were achieved by selecting the rotor speed at the appropriate rotations per minute (rpm) and adjusting the respective angle of the culture flask position to the centrifuge bottom. Consequently, constant levels of $5 \mathrm{~g}$ were attained by placement of $8-10$ culture flasks $\left(12 \mathrm{~cm}^{2}-\right.$ $24 \mathrm{~cm}^{2}$ ) in a rotor of the centrifuge at fixed distances of $13.5 \mathrm{~cm}$ from the center of rotation with a flask position to the centrifuge bottom of $78.5^{\circ}$ and a rotor speed of $180 \mathrm{rpm}$. All centrifugation experiments were performed in a temperature-controlled room $\left(37^{\circ} \mathrm{C}\right)$ in closed culture flasks saturated with $5 \% \mathrm{CO}_{2}$. In a previous report we demonstrated that exposure to hypergravity ( $2 \mathrm{~g}$ and $5 \mathrm{~g}$, but not $9 \mathrm{~g}$ ) for $12 \mathrm{~h}$ and $24 \mathrm{~h}$ induced alterations in cGMP levels in 1F6 melanoma cells with a maximal effect at $5 \mathrm{~g}$ for $24 \mathrm{~h}$ (Ivanova et al. 2004). In addition, exposure of cells to hypergravity for longer period than $24 \mathrm{~h}$ reduced the cell viability considerable. Consequently, results of changes in the expression of genes involved in cGMP signaling upon application of $5 \mathrm{~g}$ for $24 \mathrm{~h}$ are presented. In simultaneously performed $1-\mathrm{g}$ control experiments, flasks with adherent melanoma cells were placed in a horizontal position $\left(180^{\circ}\right)$ near the centrifuge for the same period of time. For subsequent analysis cells from the whole flasks were harvested.

For simulated microgravity experiments, a fast-rotating 2-D clinostat (DLR, Cologne, Germany) was used, which was originally developed by Briegleb and modified by Hauslage (DLR, Cologne Germany) for the use of commercially available slide flasks (Briegleb 1992; Ivanova et al. 2011; Eiermann et al. 2013). Briefly, the modified fast-rotating 2-D clinostat provides two parallel horizontal rotating axes, each with adapters for fixation of the slide culture flasks. In addition, the rotation of the sample around one axis is perpendicular to the direction of the gravity vector. For each experiment, 3 slide culture flasks $\left(9 \mathrm{~cm}^{2}\right)$ were inserted per rotation axis of the clinostat, which was placed in a temperature-controlled room $\left(37^{\circ} \mathrm{C}\right)$. As clinorotation generates centrifugal forces, which depends on the cell's distance from the rotation axis and the rotation speed, we used an appropriate slide chamber for harvesting of adherent cells exposed to defined maximal residual accelerations (Eiermann et al. 2013). In addition, we previously reported a maximal reduction of the GC-A mRNA levels in the investigated melanoma cells after an exposure to residual accelerations of $\leq 0.012 \mathrm{~g}$ for $24 \mathrm{~h}$ compared to 1-g control cells (Ivanova et al. 2011; Eiermann et al. 2013). Therefore, clinorotation for $24 \mathrm{~h}$ at $37{ }^{\circ} \mathrm{C}$ with a rotor speed of $60 \mathrm{rpm}$ was used in the following experiments. Using slide chambers, only cells inside an area of $6 \mathrm{~mm}$ diameter in the rotation axis ( $\mathrm{g}$-forces $\leq 0.012 \mathrm{~g}$ ) were harvested for mRNA and protein analyzes. For all experiments, 1-g controls were prepared simultaneously and placed inside the clinostat box in a horizontal position. 


\section{RNA Isolation and Real-Time Quantitative Polymerase Chain Reaction (qPCR) Analyzes}

Total RNA from melanoma cells was isolated using the RNeasy Plus ${ }^{\circledR}$ Micro kit (Qiagen, Hilden, Germany) following the manufacturer's suggestions. Briefly, reverse transcription of $1 \mu \mathrm{g}$ of total RNA was performed using random priming (QuantiTect ${ }^{\circledR}$ Reverse Transcription system, Qiagen ${ }^{\circledR}$, Hilden, Germany). The resultant single-stranded cDNA was subjected to qPCR using QantiTect ${ }^{\circledR}$ primer assays or $\mathrm{RT}^{2}$ qPCR Primer assays (Quiagen, Hilden, Germany) for GC-A (QT00081963), GC-B QT00013727), sGC- $\alpha_{1}$ (QT01001840), sGC- $\beta_{1}$ (QT00080815), eNOS (PPH01298E), iNOS (PPH00173E), PKGI (QT00001638), PDE5A (QT00048167), TYR (QT00080815), MRP4 (QT00077266), MRP5 (QT00049959), internal controls: glyceraldehyde 3-phosphate dehydrogenase (GAPDH: QT00079247), $\quad \beta$-actin (QT1680476), hypoxanthine phosphoribosyltransferase 1 (HPRT1: QT00059066), or Cyclophiline B (PPIB: QT00067186), and SYBR green as a fluorescent dye (QuantiFast SYBR Green PCR kit, Qiagen ${ }^{\circledR}$ ). No-template (water) reaction mixtures were additionally prepared as negative controls. All reactions were conducted using a LightCycler ${ }^{\circledR} 1.5$ Detector System (Roche, Mannheim, Germany). The conditions for the realtime PCR assay were $5 \mathrm{~min}$ at $95^{\circ} \mathrm{C}, 35-40$ cycles at $94^{\circ} \mathrm{C}$ for $15 \mathrm{~s}, 60^{\circ} \mathrm{C}$ for $30 \mathrm{~s}$, and $72{ }^{\circ} \mathrm{C}$ for $20 \mathrm{~s}$, following $65^{\circ} \mathrm{C}$ for $15 \mathrm{~s}$ and $40^{\circ} \mathrm{C}$ for $30 \mathrm{~s}$. The gene expression levels were calculated using the calibrator-normalized and efficiencycorrected relative quantification method (RelQuant ${ }^{\circledR}$ Software, LightCycler ${ }^{\circledR}$, Roche). We used as calibrator 1F6 melanoma cells, which were cultivated in DMEM, containing $10 \%$ FCS. Briefly, the expression level of each gene in the samples as well as of the calibrator were first normalized to the HPRT1 $\left(\Delta \mathrm{Ct}=\mathrm{CT}\right.$ targetgene $\left.-\mathrm{Ct}_{\mathrm{HPRT} 1}\right)$ and then expressed as the target gene/reference gene ratio of each sample normalized by the target gene/reference gene ratio of the calibrator.

\section{Western Blot Analysis}

For fractionated extraction of the cytosolic and membrane proteins in the investigated melanoma cells, a cell fractionation kit with different extraction buffers (membrane: CF-MEM and cytosolic: CF-CYT) containing phosphatase inhibitors was applied according to the manufacturer instructions (NanoTools, Teningen, Germany). Briefly, the buffers were supplemented with protease inhibitors using cOmplete ultra protease inhibitors cocktail tablets (Roche, Mannheim, Germany). After exposure to altered gravity, melanoma cells and control cells including transfected with siRNA for sGC- $\beta_{1}$ subunits 1F6 melanoma cells were harvested. The collected cell pellets were then resuspended with ice cold CF-CYT extraction buffer and incubated for $5 \mathrm{~min}$ at room temperature (RT). The cytosolic fractions were collected by centrifugation for $5 \mathrm{~min}$ at $1000 \times \mathrm{g}$ at $4{ }^{\circ} \mathrm{C}$. The pellets were washed, incubated with CF-MEM extraction buffer for $5 \mathrm{~min}$ at RT, and the membrane fraction was isolated by centrifugation for $5 \mathrm{~min}$ at $2000 \times$ g. Protein concentrations of the samples were analyzed using the BCA protein assay Kit (Pierce ${ }^{\circledR}$, Thermo Fisher Scientific, Langenselbold, Germany).

Aliquots of each CF-MEM buffer or CF-CYT (each $20 \mu \mathrm{g}$ protein) were subjected to sodium dodecyl sulfate polyacrylamide (SDS-PAGE) gels using Mini-PROTEAN ${ }^{\circledR}$ Tetra Cell System (Bio-Rad Laboratories GmbH, Munich, Germany) and transferred onto nitrocellulose membrane $(0.45 \mu \mathrm{m}$, Amersham Hybond ECL Nitrocellulose Membrane, GE Healthcare Europe GmbH, Freiburg, Germany) in Mini Trans-Blot ${ }^{\circledR}$ Cell System (Bio-Rad Laboratories $\mathrm{GmbH}$, Munich, Germany). Membranes were washed in Tris-buffered saline $(20 \mathrm{mM}$ Tris, $150 \mathrm{mM} \mathrm{NaCl}, \mathrm{pH}$ 7.3) containing $0.1 \%$ Tween 20 (TBST) and were blocked overnight at $4{ }^{\circ} \mathrm{C}$ (GC-B, sGC- $\beta_{1}$, and iNOS) or $90 \mathrm{~min}$ at RT (GC-A) in TBST, containing 5\% fat-free dry milk and $0.3 \%$ BSA. The membranes were then incubated with specific primary rabbit polyclonal antibodies: anti-sGC- $\beta_{1}$ (sc-20955, H-79, $65 \mathrm{kDa}$ ) and anti-GC-B (sc-25486, H-80, $120 \mathrm{kDa}$ ); with monoclonal (mousse) antibodies: anti-GC-A (sc-137041, H-80, $120 \mathrm{kDa}$ ) and anti-iNOS (sc-7271, C-11, $131 \mathrm{kDa}$ ) (all in 1:100 dilution), or anti- $\beta$-actin (sc-47778, C-4, $43 \mathrm{kDa}, 1: 2500$ dilution) for $90 \mathrm{~min}$ at RT (GC-B, sGC- $\beta 1$ and iNOS) or overnight at $4{ }^{\circ} \mathrm{C}$ (GC-A). All primary antibodies were diluted in TBST. After extensively washing with TBST, membranes were incubated with secondary goat-anti-rabbit horseradish peroxidase (HRP) conjugated IgG (sc-2030), diluted in TBST (sGC- $\beta_{1}$ and GC-B, 1:2000) or goat-anti-mouse IgG-HRP (sc-2005), diluted in TBST (iNOS, $1: 2000 ; \beta$-actin, 1:5000) for $60 \mathrm{~min}$ at RT. All antibodies were purchased from Santa Cruz Biotechnology Inc. (Heidelberg, Germany). The proteins were visualized by enhanced chemiluminescence (ECL) using ImmunoCruz ${ }^{\mathrm{TM}}$ western blotting luminol reagent (sc-2048, Santa Cruz) and the ECL Detector system (ChemiDoc ${ }^{\mathrm{TM}}$ XRS+ System, Bio-Rad, Munich, Germany).

\section{Scratch Assay}

Highly metastatic BLM melanoma cells $\left(0.2 \times 10^{6}\right)$ were seeded into $9 \mathrm{~cm}^{2}$ slide culture flasks and incubated as described in the Experimental Design Section. A scratch wound on each confluent monolayer of human BLM melanoma cells was made along the rotation axis using a sterilized $200 \mu \mathrm{l}$-tip (diameter of $600 \mu \mathrm{m}$ ). After washing 
with PBS, the cells were maintained for $2 \mathrm{~h}$ at $37^{\circ} \mathrm{C}$ and $5 \% \mathrm{CO}_{2}$ in culture flasks completely filled with mitogendeficient and phenol-red free DMEM-HEPES buffer. For subsequent analysis, the group of the $1-\mathrm{g}$ control cell monolayers ( $0 \mathrm{~h}, 6 \mathrm{~h}, 12 \mathrm{~h}$ and $24 \mathrm{~h}$ after scratching) as well as the group of the clinorotated cell monolayers $(6 \mathrm{~h}, 12 \mathrm{~h}$ and $24 \mathrm{~h}$ after scratching) were washed gently with PBS. Then, the slides were disconnected from the slide flasks and the cells were fixed using $4 \%$ formaldehyde. Finally, 2535 images of each scratch wounded BLM cell monolayer of the clinorotated slides as well as 25-35 images of each cell monolayer of the 1-g control slides were captured using an inverse microscope (Zeiss Axiovert 135) equipped with CCD-Camera Zeiss MRc5. The images were then analyzed using Zeiss AxioVison 4.83 software.

\section{Statistics}

Data obtained from centrifugation and simulated microgravity experiments were analyzed using GraphPad Prism 6.05 (GraphPad Software, Inc., La Jolla, CA, USA). The values were expressed in mean \pm SEM. Intergroup comparisons were performed by unpaired Student's t (two-tailed) with $\mathrm{P}<0.05$ considered as significant and $\mathrm{P}<0.01$ as highly significant, respectively.

\section{Results}

\section{Hypergravity Up-Regulates mRNA Expression of eNOS, sGC- $\beta_{1}$, MRP4, MRP5, and Tyrosinase in Non-metastatic Melanoma Cells}

Using a biochemical approach, we have previously shown that hypergravity (up to $5 \mathrm{~g}$ for $24 \mathrm{~h}$ ) stimulates cGMP efflux at least partly via MRP4/MRP5-dependent transport and induces an elevation in the melanin content in cultured human melanocytes and non-metastatic melanoma cell lines, expressing NO-sensitive sGC (Ivanova et al. 2004; Stieber et al. 2005), but not in highly metastatic melanoma cell lines, which do not express the sGC- $\beta_{1}$ subunit (Ivanova et al. 2004). These observations prompted us to investigate the effects of hypergravity on the mRNA expression of genes involved in cGMP signaling (e.g., NOS isoforms, sGC and GC-A/GC-B) in non-metastatic 1F6 and highly metastatic BLM melanoma cells. In pigmented 1F6 melanoma cells (Fig. 1a), hypergravity (5 g for $24 \mathrm{~h}$ ) enhanced predominantly the relative mRNA expression of eNOS ( $5 \mathrm{~g} / 1 \mathrm{~g}$ ratio: $1.31 \pm 0.01)$, sGC- $\beta_{1}(5 \mathrm{~g} / 1 \mathrm{~g}$ ratio: $1.19 \pm 0.02)$, MRP4 ( $5 \mathrm{~g} / 1 \mathrm{~g}$ ratio: $1.24 \pm 0.04)$ and MRP5 $(5 \mathrm{~g} / 1 \mathrm{~g}$ ratio: $1.39 \pm 0.02)$, and TYR $(5 \mathrm{~g} / 1 \mathrm{~g}$ ratio: 1.42 \pm 0.03 ), a key enzyme in melanin synthesis.
To further study the dependence of hypergravity effects on the presence of NO-sensitive sGC, we performed hypergravity experiments with 1F6 melanoma cells transfected with siRNA against the sGC- $\beta_{1}$ subunit (Fig. 1b). The down-regulation of the sGC- $\beta_{1}$ expression was revealed by real-time qPCR $(75 \% \pm 4.2 \%)$ as well as by Western blot analysis, respectively (Fig. 1b). Whereas the hypergravityinduced up-regulation in the mRNA levels of expression of eNOS, MRP4, and MRP5 in parental cells was fully reversed in the transfected cells in comparison to 1- $g$ controls, the respective mRNA levels of the TYR were still detectable $(5 \mathrm{~g} / 1 \mathrm{~g}$ ratio: $1.14 \pm 0.02)$ (Fig. 1b). Together, these results indicate that eNOS-sGC-cGMP-MRP4/MRP5 signaling is up-regulated in non-metastatic melanoma cells at hypergravity compared to $1 \mathrm{~g}$.

In contrast, hypergravity (5 $\mathrm{g}$ for $24 \mathrm{~h}$ ) did not significantly alter the GC-A and GC-B mRNA expression in 1F6 melanoma cells (Fig. 1a) as well as in 1F6 melanoma cells transfected with siRNA against the sGC- $\beta_{1}$ subunit (Fig. 1b) and in highly metastatic BLM melanoma cells (Fig. 1c). Finally, the mRNA expression of eNOS and iNOS are also not affected in centrifuged highly metastatic BLM melanoma cells compared to 1 -g controls (Fig. 1c). Thus, whereas GC-A/GC-B-cGMP-dependent signaling appears to be insensitive to increased accelerations in non-metastatic 1F6 and highly metastatic BLM melanoma cells, the e/iNOS-dependent cGMP signaling remains unchanged only in highly metastatic BLM melanoma cells.

\section{Simulated Microgravity Down-Regulates Expression of GC-cGMP Signaling Components}

Using a fast-rotating 2-D clinostat (60 rpm), we have studied the effect of simulated microgravity $(\leq 0.012 \mathrm{~g}$ for 24 $h$ ) on the expression of genes involved in GC-cGMP signaling in human 1F6 and BLM melanoma cells as examples for melanoma cells expressing different GC isoforms. In our previous report we showed down-regulation of GC-A and GC-B mRNA expression in both cell types at simulated microgravity conditions in comparison to 1-g controls (Ivanova et al. 2011). Here, we demonstrate a reduction in the relative mRNA expression $(\leq 0.012 \mathrm{~g} / 1 \mathrm{~g}$ ratio $)$ of eNOS $(0.71 \pm$ $0.04)$, sGC- $\beta_{1}(0.76 \pm 0.05)$, MRP4 (0.69 \pm 0.07$)$, MRP5 $(0.74 \pm 0.02)$, but not in TYR mRNA levels in 1F6 melanoma cells after cell exposure to simulated microgravity (Fig. 2a). In addition, the relative mRNA values for GC-A $(0.55 \pm$ $0.04)$ and GC-B $(0.53 \pm 0.03)$ presented in the figure are similar to previously published (Ivanova et al. 2011).

In order to study whether the down-regulation of the expression of the cGMP signaling components in 1F6 melanoma cells depends on the presence of NO-sensitive sGC, we compared the mRNA expression levels of eNOS, iNOS, 


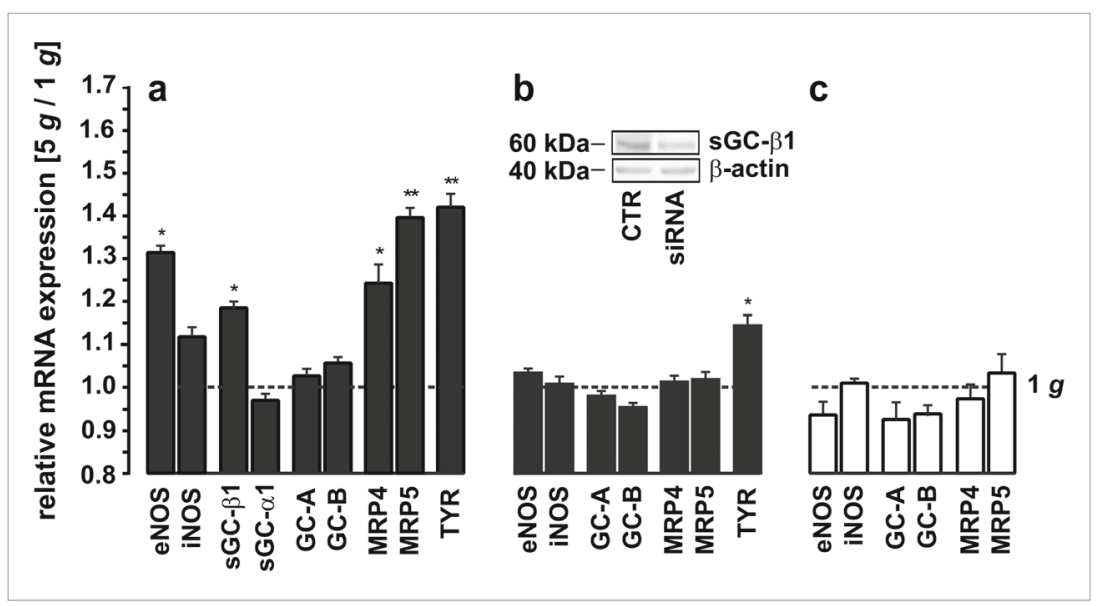

Fig. 1 Hypergravity up-regulates mRNA expression of eNOS-sGCMRP4/MRP5 signaling in human melanoma cells expressing functional sGC. a Relative mRNA expression of eNOS/iNOS, sGC$\alpha_{1} / \mathrm{sGC}-\beta_{1}, \mathrm{GC}-\mathrm{A} / \mathrm{GC}-\mathrm{B}, \mathrm{MRP} 4 / \mathrm{MRP} 5$, and TYR in non-metastatic 1F6 melanoma cells. b Relative mRNA expression of eNOS/iNOS, GC-A/GC-B, MRP4/MRP5, and TYR in 1F6 melanoma cells transfected with siRNA against the sGC- $\beta_{1}$ subunit or with scrambled siRNA. Representative Western blots for detecting the efficiency of sGC- $\beta_{1}$ subunit downregulation in transfected $1 \mathrm{~F} 6$ melanoma cells in comparison to control cells (CTR) and of $\beta$-actin as a loading control. c Relative mRNA expression of eNOS/iNOS, GC-A/GC-B, and
MRP4/MRP5 in highly metastatic BLM melanoma cells. All investigated human melanoma cells were exposed to $5 \mathrm{~g}$ using the STATEX II centrifuge or to $1 \mathrm{~g}$ for $24 \mathrm{~h}$. The relative mRNA expression (5 $\mathrm{g} / 1 \mathrm{~g}$ ) of eNOS/iNOS, sGC- $\alpha_{1} / \mathrm{sGC}-\beta_{1}$, GC-A/GC-B, MRP4/MRP5 and TYR were measured by quantitative real-time PCR analysis using calibrator-normalized and efficiency-corrected relative quantification method (LightCycler®, Roche, Mannheim, Germany). Data in bar graphs (black bars-non-metastatic 1F6 melanoma cells; white barshighly metastatic BLM melanoma cells), are mean \pm SEM from three to six independent experiments in quadruplicate cultures analyzed in duplicates. *, $\mathrm{P}<0.05$, **, $\mathrm{P}<0.001$ vs. $1-g$ control groups

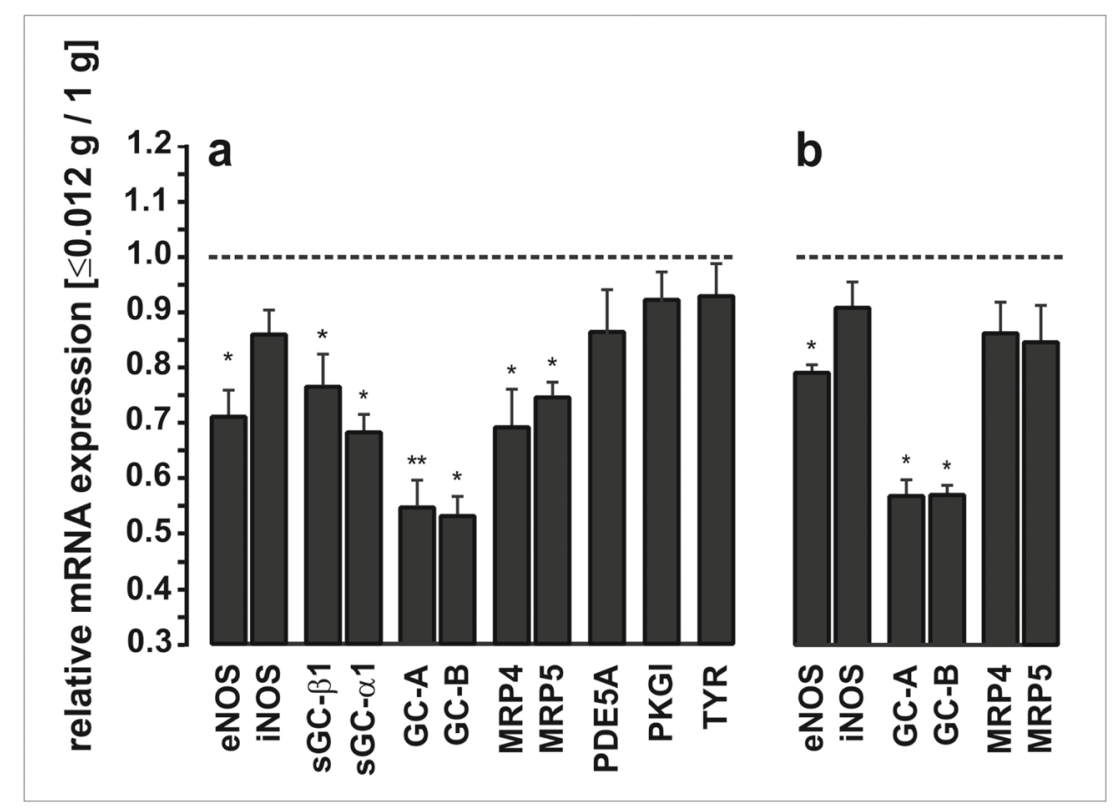

Fig. 2 Simulated microgravity down-regulates mRNA expression of GC-cGMP signaling components in non-metastatic human melanoma cells. a Relative mRNA expression of eNOS/iNOS, sGC- $\alpha_{1} / \mathrm{sGC}$ $\beta_{1}$, GC-A/GC-B, MRP4/MRP5, PDE5A, PKGI, and TYR in nonmetastatic 1F6 melanoma cells. b Relative mRNA expression of eNOS/iNOS, GC-A/GC-B, and MRP4/MRP5 in 1F6 melanoma cells transfected with siRNA against the sGC- $\beta_{1}$ subunit or with scrambled siRNA. The investigated human melanoma cells were exposed for $24 \mathrm{~h}$ to simulated microgravity ( $\mathrm{g}$-forces range $\leq 0.012 \mathrm{~g}$ ) using a fast-rotating 2-D clinostat or to $1 \mathrm{~g}$. The relative mRNA expression of the investigated genes was measured by quantitative real-time RT-PCR analysis using calibrator-normalized and efficiency-corrected relative quantification method (LightCycler®, Roche, Mannheim, Germany). Data are means \pm SEM from three to five independent experiments of sixplicate cultures and pooled fractions of two cultures of each experiment were analyzed in duplicates. $*, \mathrm{P}<0.05, * *, \mathrm{P}<0.001$ vs. $1-\mathrm{g}$ control groups 
GC-A, GC-B, MRP4, and MRP5 in 1F6 cells transfected with siRNA against $\mathrm{sGC}-\beta_{1}$ with the respective levels in parental cells (Fig. 2b). The results show that the transfection induced a partial reduction in the simulated microgravity-induced down-regulation of the relative mRNA expression $(\leq 0.012 \mathrm{~g} / 1 \mathrm{~g}$ ratio) for eNOS $(0.79$ $\pm 0.01)$, MRP4 (0.86 \pm 0.06$)$ and MRP5 (0.85 \pm 0.7$)$ in transfected 1F6 melanoma cells (Fig. 2b) when compared to parental cells (Fig. 2a).

The most potent simulated microgravity-induced downregulation of the investigated relative mRNA values ( $\leq 0.012 \mathrm{~g} / 1 \mathrm{~g}$ ratio) was found in highly metastatic BLM melanoma cells for iNOS (0.69 \pm 0.04$)$, GC-A $(0.55$ $\pm 009)$ and GC-B $(0.53 \pm 0.03)$ (Fig. 3a). The mRNA levels of expression presented for GC-B and GC-A are similar to results of our published report (Ivanova et al. 2011). Further, the MRP5 mRNA expression is significantly down-regulated in simulated microgravity compared to $1 \mathrm{~g}$, whereas the mRNA level of MRP4 is not affected (Fig. 3a).

We additionally determined the effects of simulated microgravity on the mRNA expression of the PDE5A, which is controlling the cytosolic cGMP levels, as well as the mRNA expression of PKGI, which phosphorylates serine and threonine residues in many cellular proteins. As shown in Fig. 2a for non-metastatic 1F6 and in Fig. 3a for highly metastatic BLM melanoma cells, we observed a significant reduction of PKGI only in highly metastatic BLM melanoma cells, but no changes of the PDE5A expression in both clinorotated cells when compared to 1-g control levels.

Finally, as the most potent simulated microgravityinduced down-regulation of the investigated mRNA expression was found for the cancer-related genes iNOS, GC-A and GC-B when compared to $1 \mathrm{~g}$, we measured additionally the protein levels of iNOS, GC-A and GC-B using Western blot analysis. The protein levels of GC-A $(\sim 120 \mathrm{kDa})$, GC-B $(\sim 140 \mathrm{kDa})$ and iNOS $(\sim 130 \mathrm{kDa})$ in BLM human melanoma cells reflect the patterns seen with the respective mRNA levels (Fig. 3b).

\section{Simulated Microgravity Induces Anti-Migratory Effects in Highly Metastatic BLM Melanoma Cells}

As expression of the GC-A and GC-B in melanoma cells appears to correlate to metastatic potential (Ivanova et al. 2001; Kong et al. 2008) and we previously reported down-regulation of GC-A and GC-B expression in highly metastatic BLM melanoma cells after exposure to simulated microgravity in the range of $\leq 0.012 \mathrm{~g}$ for the time period of both $6 \mathrm{~h}$ and $24 \mathrm{~h}$ (Ivanova et al. 2011), we applied a scratch assay to study the effects of simulated microgravity on the migration of the BLM melanoma cells.

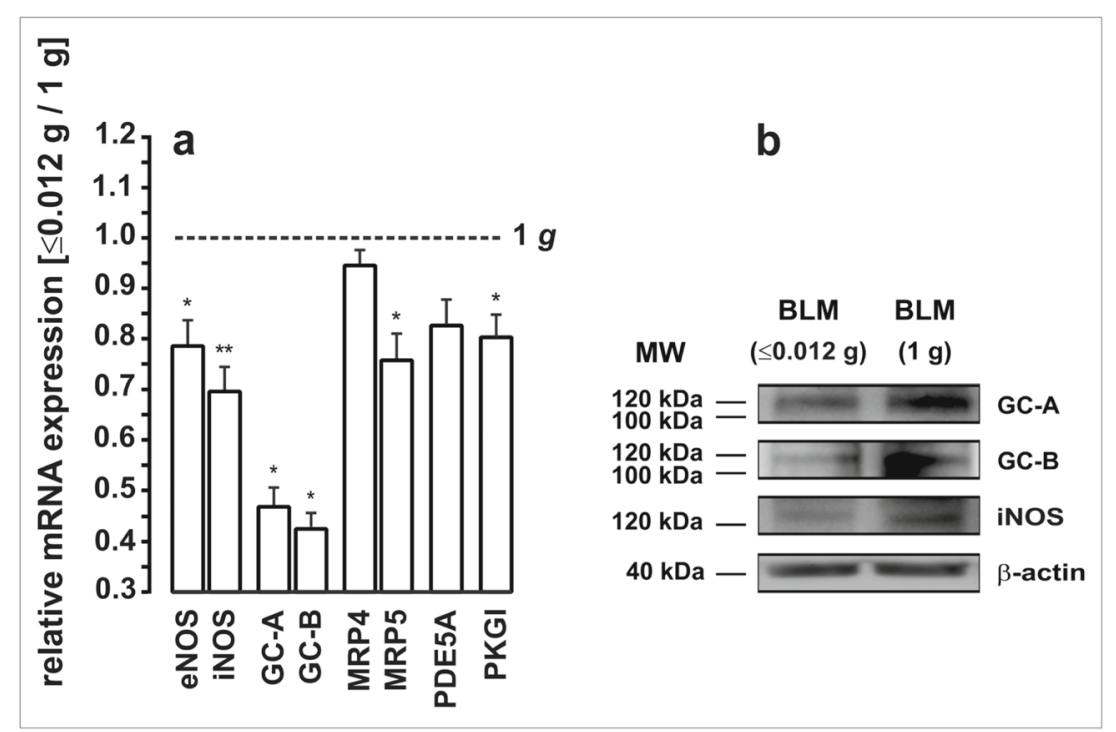

Fig. 3 Expression of e/iNOS-GC-cGMP-MRP4/MRP5 signaling components in highly metastatic human melanoma cells. a Relative mRNA expression of eNOS/iNOS, GC-A/GC-B, MRP4/MRP5, PDE5A, and PKGI in highly metastatic BLM melanoma cells. The investigated human melanoma cells were exposed for $24 \mathrm{~h}$ to simulated microgravity (g-forces range $\leq 0.012 \mathrm{~g}$ ) using a fast-rotating 2 -D clinostat or to $1 \mathrm{~g}$. The relative mRNA expression of the investigated genes was measured by quantitative real-time RT-PCR analysis using calibrator-normalized and efficiency-corrected relative quantification method (LightCycler®, Roche, Mannheim, Germany). Data are means \pm SEM from three to five independent experiments of sixplicate cultures and pooled fractions of two cultures of each experiment were analyzed in duplicates. b Representative Western blots of the protein expression of GC-A/GC-B (membrane fractions), iNOS (cytosolic fraction), and $\beta$-actin as a loading control in highly metastatic BLM melanoma cells. The results were confirmed in three independent experiments using sixplicate cultures and pooled protein of each experiment was analyzed. *, $\mathrm{P}<0.05, * *, \mathrm{P}<0.001$ vs. 1 -g control groups 
In addition, results of a live cell imaging by means of a fast-rotating clinostat microscope $(60 \mathrm{rpm})$ indicated that highly metastatic melanoma BLM cells are able to detach, migrate and attach again without any sign of apoptosis during clinorotation for $6 \mathrm{~h}$ (Ivanova et al. 2011).

Here, we present results for effects of simulated microgravity $(\leq 0.012 \mathrm{~g})$ on the BLM melanoma cell migration at $6 \mathrm{~h}, 12 \mathrm{~h}$ and $24 \mathrm{~h}$ after scratching in comparison to $1-\mathrm{g}$ controls. Figure $4 \mathrm{a}$ shows the quantitative evaluation of the cell-free wound areas at the investigated time points reflected by percentage of the initial scratch area at $\mathrm{t}=0 \mathrm{~h}(100 \%)$. In addition, the variation in the initial scratches of the sample was of approximately $5.1 \%$. In the scratch assay, simulated microgravity $(\leq 0.012 \mathrm{~g})$ reduced significantly the number of the cells in the wounded region of the BLM melanoma cell monolayers at $6 \mathrm{~h}$ and $12 \mathrm{~h}$ after scratching compared to the corresponding 1-g controls (e.g., $1 \mathrm{~g}$ for $6 \mathrm{~h}: 57.7 \% \pm 4.0 \%$, clinorotation for $6 \mathrm{~h}: 69.2 \%$ $\pm 3.1 \% ; 1 \mathrm{~g}$ for $12 \mathrm{~h}: 32.6 \% \pm 2.4 \%$, clinorotation for $12 \mathrm{~h}: 38.5 \% \pm 2.7 \%$ ). Finally, the wound areas of the $1-\mathrm{g}$ control BLM melanoma cell monolayers were completely closed after incubation for $24 \mathrm{~h}$ at $37{ }^{\circ} \mathrm{C}$, whereas in the clinorotated cell monolayers approximately $5 \%$ of the wound area remained. In addition, representative images of the wound areas of BLM melanoma cell monolayers immediately $(0 \mathrm{~h})$ as well as of the wound areas of cell monolayers exposed to simulated microgravity $(\leq 0.012 \mathrm{~g})$ and of the wound areas under control conditions ( $1 \mathrm{~g})$ at $6 \mathrm{~h}$ after scratching are shown in Fig. 4b. The wound closures of the clinorotated for $6 \mathrm{~h}$ highly metastatic BLM melanoma cell monolayers converged more slowly in comparison to the wound closures of the respective 1$\mathrm{g}$ control cell monolayers, indicating a reduction of the migratory potential of the cells in simulated microgravity.

\section{Discussion}

In previous studies, we have demonstrated differential expression of functional guanylyl cyclase isoforms in human melanocyte and melanoma cells as well as an involvement of cGMP in the response of melanocytes to gravity changes. The present results indicate that hypergravity and simulated microgravity inversely modulate the expression of GC-cGMP signaling components in human melanoma cells. The most important finding is that simulated microgravity down-regulates the expression of the cancer-related genes iNOS, GC-A and GC-B in highly metastatic melanoma cell as well as motility, suggesting a reduction of the melanoma aggressiveness in microgravity condition.

In this study, we used human melanoma cell lines with different metastatic potential and pigmentation to investigate the effects of altered gravity on the expression of GCcGMP signaling components. In pigmented 1F6 melanoma cells, hypergravity ( $5 \mathrm{~g}$ for $24 \mathrm{~h}$ ) induces an increase in the mRNA expression of eNOS and MRP4/MRP5, but there are no apparent changes in the mRNA expression of GC-A/GC-B when compared to $1-\mathrm{g}$ controls. Thus, eNOS-cGMP signaling seems to be involved in the previously reported hypergravityinduced and MRP4/MRP5-dependent cGMP efflux in melanoma cells expressing functional sGC (Ivanova et al.

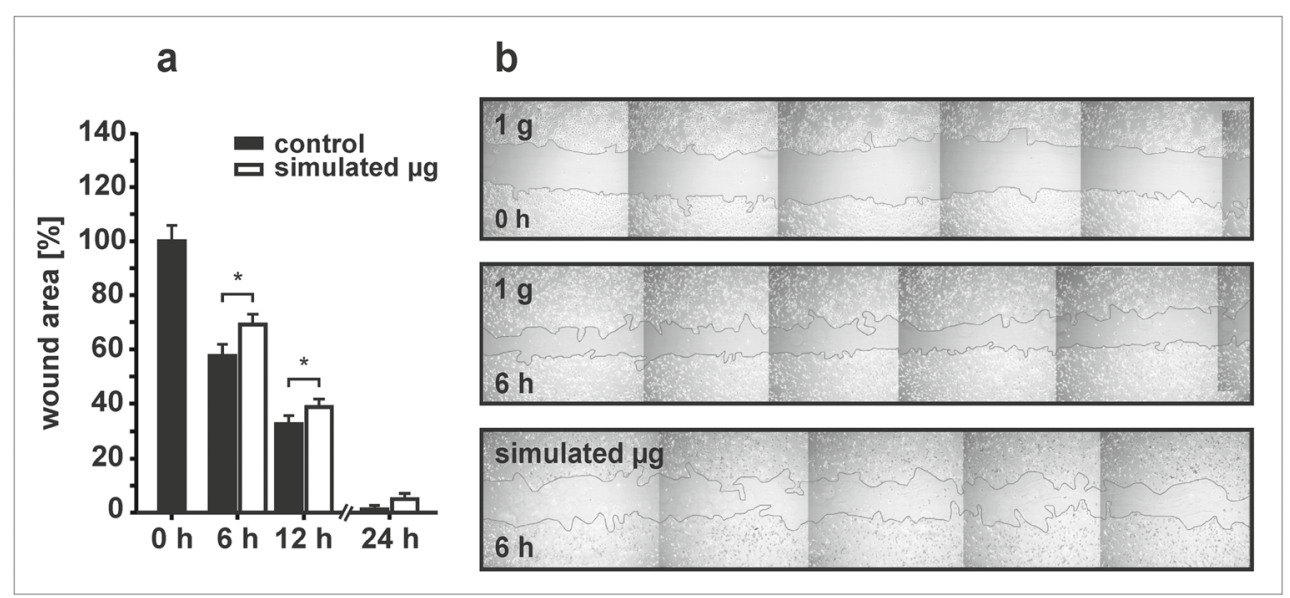

Fig. 4 Simulated microgravity reduces motility of highly metastatic melanoma cells in vitro. $\mathbf{a}$ and $\mathbf{b}$ Analysis of highly metastatic human BLM melanoma cell migration by a scratch assay. Confluent monolayers of cells were wounded $(0 \mathrm{~h})$ and then exposed for $6 \mathrm{~h}, 12 \mathrm{~h}$ or $24 \mathrm{~h}$ to simulated microgravity (simulated $\mu \mathrm{g}$; g-forces range $\leq 0.012$ g) or under control conditions ( $1 \mathrm{~g})$. a Quantitative evaluation of cell migration at the investigated time points reflected in percentage of the initial scratch area at $\mathrm{t}=0 \mathrm{~h}(100 \%)$. Data in bar graphs are mean \pm SEM from three to four independent experiments in triplicate cultures (*, P $<0.05$ vs. 1 - $g$ control groups). b Representative images of BLM melanoma cell monolayers immediately $(\mathrm{t}=0 \mathrm{~h})$ as well as after exposure for $6 \mathrm{~h}$ to simulated $\mu \mathrm{g}$ or under $1 \mathrm{~g}$-control conditions after initiating a scratch wounds on confluent slide culture flasks 
2004). Moreover, hypergravity was unable to induce changes in the mRNA expression of eNOS, MRP4/MRP5 in 1F6 melanoma cells transfected with siRNA against the sGC- $\beta_{1}$ subunit, indicating that a cytosolic-localized pool of elevated cGMP is targeted by hypergravity. As we did not observe previously marked changes in the morphology and proliferation in the accelerated cells in comparison to 1-g controls (Ivanova et al. 2004), it is suggested that the reduction of intracellular cGMP concentration due to enhanced expression of MRP4/MRP5 as cGMP exporter may play a role in the adaptation of melanoma cells to hypergravity. However, future in vivo studies under hypergravity conditions should contribute to clarify whether the extracellular cGMP has a signaling function in adjacent cells or processes in the tumor microenvironment. In addition, the finding that hypergravity does not alter the mRNA expression of e/iNOS, GC-A/GC-B and MRP4/MRP5 in metastatic melanoma cells compared to 1-g controls support our previous observation that melanoma cells, which do not express functional sGC, are apparently insensitive to hypergravity effects (Ivanova et al. 2004).

In a previous study we also reported a relationship between hypergravity-induced increase in melanin content and increases in both intra- and extracellular levels of cyclic adenosine- $3^{\prime}, 5^{\prime}$-monophosphate (cAMP) (Ivanova et al. 2004), a well-known modulator of melanogenesis in melanocytes (Park and Gilchrest 1999). Interestingly, our current data demonstrate that the hypergravity-induced increase in the mRNA expression of tyrosinase in pigmented 1F6 melanoma cells is partly reversed in 1F6 cells transfected with siRNA against sGC- $\beta_{1}$ subunit, suggesting a partial role of cGMP signaling in the hypergravityinduced pigmentation. In addition, a role of sGC-cGMP signaling was shown in the UVB-generated NO as one of the melanogens acting via enhancement of tyrosinase gene expression as a primary mechanism of NO-induced melanogenesis (Sasaki et al. 2000). Thus, hypergravity can be considered as another stimulus that is able to enhance at least partly melanin content in pigmented human melanocytic cells expressing NO-sensitive sGC. This finding could be of importance for humans being exposed to hypergravity environment.

In contrast to the hypergravity effects, simulated microgravity was found to down-regulate the eNOS-sGC-MRP4/MRP5 signaling in pigmented 1F6 melanoma cells. Silencing of the sGC- $\beta_{1}$ subunit expression in 1F6 melanoma cells reversed slightly the simulated microgravity-induced down-regulation in the mRNA expression of eNOS and MRP4/MRP5, indicating that down-regulation of MRP4 and MRP5 expression is only partly dependent on the presence of NO-sensitive sGC. Regarding the simulated microgravity-induced down-regulation of NO-sensitive sGC expression in non-metastatic melanoma cells, it can be suggested that this type of melanoma cells may undergo malignant transformation during long-term-exposure to microgravity environment, as suppression of sGC expression and activities have been proposed as a biomarker for tumor aggressiveness (Mujoo et al. 2010).

In the present study, we further demonstrate downregulation of iNOS expression in the investigated metastatic melanoma cells under simulated microgravity condition. As iNOS expression is absent in benign nevi and present in invasive melanoma (Massi et al. 2001), and the levels of expression correlates strongly with poor clinical outcome (Ekmekcioglu et al. 2000, 2006), the down-regulation of iNOS mRNA expressions in highly metastatic BLM melanoma cells may also contribute to the reduction of melanoma aggressiveness in the microgravity environment. Importantly, as shown in our previous studies (Ivanova et al. 2011) and verified here additionally on protein level, simulated microgravity induces down-regulation of the expression of both ANP-responsible GC-A and CNPresponsible $\mathrm{GC}-\mathrm{B}$ in the investigated metastatic melanoma cells in comparison to $1-\mathrm{g}$ controls. Moreover, our current data indicate a reduction in the motility of clinorotated highly metastatic BLM melanoma cells in comparison to 1 -g control cells, which is in agreement with a reported reduction of migration for human lung adenocarcinoma cell line (Chang et al. 2013) as well as for human glioblastoma U87 cells during clinorotation (Shi et al. 2015). In addition, very recent report shows that the ability of fibroblasts to migrate was significantly impaired at modeled microgravity conditions using a Rotary cell culture system (Cialdai et al. 2017). However, whether the reduction of the migratory potential of BLM melanoma cells depends only on the reduction in GC-A and GC-B expression or other contributing factors remains to be investigated.

Interestingly, we further found down-regulation of the expression of PKGI and MRP5, but not for MRP4 in these cells. In addition, it has been documented that CNP, which can be secreted by endothelial cell, particularly under inflammatory conditions (Potter et al. 2006), enhances the activity of PKGI in melanoma cells by increasing the intracellular levels of cGMP (Dhayade et al. 2016). Activation of this cGMP pathway promotes melanoma cell growth and migration in both in vitro and in vivo in preclinical melanoma model (Dhayade et al. 2016). Expression analysis of a panel of human melanoma cells and tumor sections of human melanoma patients further indicated that PGKI is probably not the only effector of cGMP in melanoma cells that may reflect the well-known heterogeneity of melanoma cells (Dhayade et al. 2016). Moreover, it is well known that the cell microenvironment in vivo strongly affects malignant transformation and metastatic behavior of cancer cells. In addition, cGMP signaling may also affect various 
processes in the tumor microenvironment such as blood flow, angiogenesis, inflammation, and immune response. However, future in vivo studies are needed to elucidate the potential role and the mechanism of cGMP signaling in melanocyte transformation in real microgravity.

In conclusion, the results of the present in vitro study demonstrate differential effects of altered gravity on the expression of genes involved in guanylyl cyclase-cGMP signaling in human melanoma cells. Whereas hypergravity induces an up-regulation of eNOS-sGC-cGMP-MRP4/5 signaling pathway in non-metastatic melanoma cells, in highly metastatic cells both e/iNOS and GC-A/GC-BcGMP signaling pathways remained insensitive to hypergravity when compared to $1 \mathrm{~g}$. The present data further suggest that hypergravity can be considered as a melanogenic stimulus in pigmented melanoma cells expressing NOsensitive sGC, as it is able to induce a sGC-dependent increase in tyrosinase expression in these cells. Most importantly, simulated microgravity induces down-regulation in the expression of cancer-related genes iNOS and GC-A/GC$\mathrm{B}$ in highly metastatic human melanoma cells, but also down-regulation of the NO-sensitive sGC expression in non-metastatic melanoma cells, whose expression and activity have been inversely related to tumor aggressiveness. The results suggest that future studies in real microgravity can benefit from considering GC-cGMP signaling as a possible factor for melanocyte transformation as well as by the adaptation of medication regimes in future spaceflights.

Acknowledgments Peter Eiermann received a Helmholtz Space Life Sciences Research School (SpaceLife) Scholarship. SpaceLife is funded in equal parts by the Helmholtz Association and the German Aerospace Center (DLR).

\section{Compliance with Ethical Standards}

Competing Interests The authors declare that they have no competing interests.

Abbreviations ANP, Atrial natriuretic peptide; cAMP, Cyclic adenosine- $3^{\prime}, 5^{\prime}$-monophosphate; cGMP, Cyclic guanosine- $3^{\prime}, 5^{\prime}$ monophosphate; CNP, C-type natriuretic peptide; ECM, Extracellular Matrix; GC, Guanylyl cyclase; GC-A, Guanylyl cyclase A; GC-B, Guanylyl cyclase B; eNOS, Endothelial nitric oxide synthase; iNOS, Inducible nitric oxide synthase MRP4Multidrug resistance-associated protein 4; MRP5, Multidrug resistance-associated protein; $\mu g$, Microgravity; NO, Nitric oxide; NOS, Nitric oxide synthase; PDE5, cGMP-regulated phosphodiesterase; PKGI, cGMP-dependent protein kinase I; TYR, Tyrosinase; sGC, Soluble guanylyl cyclase; UV, Ultraviolet.

Open Access This article is distributed under the terms of the Creative Commons Attribution 4.0 International License (http:// creativecommons.org/licenses/by/4.0/), which permits unrestricted use, distribution, and reproduction in any medium, provided you give appropriate credit to the original author(s) and the source, provide a link to the Creative Commons license, and indicate if changes were made.

\section{References}

Aleshcheva, G., Bauer, J., Hemmersbach, R., Egli, M., Wehland, M., Grimm, D.: Tissue engineering of cartilage on ground-based facilities. Microgravity Sci. Tecnol. 28, 237-245 (2016)

Beavo, J.A., Brunton, L.L.: Cyclic nucleotide research-still expanding after half a century. Nat. Rev. Mol. Cell Biol. 3, 710-718 (2002)

Bian, K., Ghassemi, F., Sotolongo, A., Siu, A., Shauger, L., Kots, A., Murad, F.: NOS-2 signaling and cancer therapy. IUBMB Life 64, 676-683 (2012)

Biel, M., Michalakis, S.: Cyclic nucleotide-gated channels. Hand. Exp. Pharmacol. 191, 111-136 (2009)

Briegleb, W.: Some qualitative and quantitative aspects of the fast-rotating clinostat as a research tool. ASGSB Bull. 5, 23-30 (1992)

Brungs, S., Egli, M., Wuest, S.L., Christianen, P.C.M., van Loon, J.J.W.A., Anh, T.J.N., Hemmersbach, R.: Facilities for simulation of microgravity in the ESA ground-based facility programme. Microgravity Sci. Technol. 28, 191-203 (2016)

Cialdai, F., Vignali, L., Morbidelli, L., Colciago, A., Celotti, F., Santi, A., Caselli, A., Cirri, P., Monici, M.: Modeled microgravity affects fibroblast functions related to wound healing. Microgravity Sci Technol. 29, 121-132 (2017)

Chang, D., Xu, H., Guo, Y., Jiang, X., Liu, Y., Li, K., Pan, C., Yuan, M., Wang, J., Li, T., Liu, C.: Simulated microgravity alters the metastatic potential of a human lung adenocarcinoma cell line. In Vitro Cell Dev. Biol. Anim. 49, 170-177 (2013)

Conti, M., Beavo, J.: Biochemistry and physiology of cyclic nucleotide phosphodiesterases: essential components in cyclic nucleotide signaling. Annu. Rev. Biochem. 76, 481-511 (2007)

Danen, E.H.J., van Muijen, G.N.P., van de Wiel-van Kemenade, E., Jansen, K.F.J., Ruiter, D.J., Figor, C.G.: Regulation of integrinmediated adhesion to laminin and collagen in human melanocytes and in non-metastatic and highly metastatic human melanoma cells. Int. J. Cancer 54, 315-321 (1993)

Deeley, R.G., Westlake, C., Cole, S.P.: Transmembrane transport of endo- and xenobiotics by mammalian ATP-binding cassette multidrug resistance proteins. Physiol. Rev. 86, 849-899 (2006)

Derbyshire, E.R., Marletta, M.A.: Structure and regulation of soluble guanylate cyclase. Annu. Rev. Biochem. 81, 533-559 (2012)

Dhayade, S., Kaesler, S., Sinnberg, T., Dobrowinski, H., Peters, S., Naumann, U., Liu, H., Hunger, R.E., Thunemann, M., Biedermann, T., Schittek, B., Simon, H.U., Feil, S., Feil, R.: Sildenafil potentiates a cGMP-dependent pathway to promote melanoma growth. Cell Rep. 14, 2599-2610 (2016)

Eiermann, P., Kopp, S., Hauslage, J., Hemmersbach, R., Gerzer, R., Ivanova, K.: Adaptation of a 2-D clinostat for simulated microgravity experiments with adherent cells. Microgravity Sci. Technol. 25, 153-159 (2013)

Ekmekcioglu, S., Ellerhorst, J., Smid, C.M., Prieto, V.G., Munsell, M., Buzaid, A.C., Grimm, E.A.: Inducible nitric oxide synthase and nitrotyrosine in human metastatic melanoma tumors correlate with poor survival. Clin. Cancer Res. 6, 4768-4775 (2000)

Ekmekcioglu, S., Ellerhorst, J.A., Prieto, V.G., Johnson, M.M., Broemeling, L.D., Grimm, E.A.: Tumor iNOS predicts poor survival for stage III melanoma patients. Int. J. Cancer 119, 861866 (2006)

Fajardo, A.M., Piazza, G.A., Tinsley, H.N.: The role of cyclic nucleotide signaling pathways in cancer: targets for prevention and treatment. Cancers 6, 436-458 (2014)

Frippiat, J.P., Crucian, B.E., de Quervain, D.J., Grimm, D., Montano, N., Praun, S., Roozendaal, B., Schelling, G., Thiel, M., Ullrich, O., Chouker, A.: Towards human exploration of space: the THESEUS review series on immunology research priorities. NPJ Microgravity 2, 16040 (2016) 
Gerzer, R., Bohme, E., Hofmann, F., Schultz, G.: Soluble guanylate cyclase purified from bovine lung contains heme and copper. FEBS Lett. 132, 71-74 (1981)

Grimm, E.A., Ellerhorst, J., Tang, C.H., Ekmekcioglu, S.: Constitutive intracellular production of iNOS and NO in human melanoma: possible role in regulation of growth and resistance to apoptosis. Nitric Oxide 19, 133-137 (2008)

Herranz, R., Anken, R., Boonstra, J., Braun, M., Christianen, P.C., de Geest, M., Hauslage, J., Hilbig, R., Hill, R.J., Lebert, M., Medina, F.J., Vagt, N., Ullrich, O., van Loon, J.J., Hemmersbach, R.: Ground-based facilities for simulation of microgravity: organismspecific recommendations for their use, and recommended terminology. Astrobiology 13, 1-17 (2013)

Hofmann, F.: The biology of cyclic GMP-dependent protein kinases. J. Biol. Chem. 280, 1-4 (2005)

Hughes-Fulford, M.: Function of the cytoskeleton in gravisensing during spaceflight. Adv. Space Res. 32, 1585-1593 (2003)

Hughes-Fulford, M., Lewis, M.L.: Effects of microgravity on osteoblast growth activation. Exp. Cell Res. 224, 103-109 (1996)

Ignarro, L.J.: Haem-dependent activation of guanylate cyclase and cyclic GMP formation by endogenous nitric oxide: a unique transduction mechanism for transcellular signaling. Pharmacol. Toxicol. 67, 1-7 (1990)

Ivanova, K., Le Poole, I.C., Gerzer, R., Westerhof, W., Das, P.K.: Effect of nitric oxide on the adhesion of human melanocytes to extracellular matrix components. J. Pathol. 183, 469-476 (1997)

Ivanova, K., Das, P.K., van den Wijngaard, R.M., Lenz, W., Klockenbring, T., Malcharzyk, V., Drummer, C., Gerzer, R.: Differential expression of functional guanylyl cyclases in melanocytes: absence of nitric-oxide-sensitive isoform in metastatic cells. J. Invest. Dermatol. 116, 409-416 (2001)

Ivanova, K., Zadeh, N.H., Block, I., Das, P.K., Gerzer, R.: Stimulation of cyclic GMP efflux in human melanocytes by hypergravity generated by centrifugal acceleration. Pigm. Cell Res. 17, 471-479 (2004)

Ivanova, K., van den Wijngaard, R., Gerzer, R., Lamers, W.H., Das, P.K.: Non-lesional vitiliginous melanocytes are not characterized by an increased proneness to nitric oxide-induced apoptosis. Exp. Dermatol. 14, 445-453 (2005)

Ivanova, K., Lambers, B., van den Wijngaard, R., Le Poole, I.C., Grigorieva, O., Gerzer, R., Das, P.K.: Immortalization of human melanocytes does not alter the de novo properties of nitric oxide to induce cell detachment from extracellular matrix components via cGMP. In Vitro Cell Dev. Biol. Anim. 44, 385-395 (2008)

Ivanova, K., Eiermann, P., Tsiockas, W., Hauslage, J., Hemmersbach, R., Gerzer, R.: Natriuretic peptide-sensitive guanylyl cyclase expression is down-regulated in human melanoma cells at simulated weightlessness. Acta Astronaut. 68, 652-655 (2011)

Jedlitschky, G., Burchell, B., Keppler, D.: The multidrug resistance protein 5 functions as an ATP-dependent export pump for cyclic nucleotides. J. Biol. Chem. 275, 30069-30074 (2000)

Kong, X., Wang, X., Xu, W., Behera, S., Hellermann, G., Kumar, A., Lockey, R.F., Mohapatra, S., Mohapatra, S.S.: Natriuretic peptide receptor a as a novel anticancer target. Cancer Res. 68, 249-256 (2008)

Le Poole, I.C., van den Berg, F.M., van den Wijngaard, R.M., Galloway, D.A., van Amstel, P.J., Buffing, A.A., Smits, H.L., Westerhof, W., Das, P.K.: Generation of a human melanocyte cell line by introduction of HPV16 E6 and E7 genes. In Vitro Cell Dev. Biol. Anim. 33, 42-49 (1997)

Lucas, K.A., Pitari, G.M., Kazerounian, S., Ruiz-Stewart, I., Park, J., Schulz, S., Chepenik, K.P., Waldman, S.A.: Guanylyl cyclases and signaling by cyclic GMP. Pharmacol. Rev. 52, 375-414 (2000)

Massi, D., Franchi, A., Sardi, I., Magnelli, L., Paglierani, M., Borgognoni, L., Maria Reali, U., Santucci, M.: Inducible nitric oxide synthase expression in benign and malignant cutaneous melanocytic lesions. J. Pathol. 194, 194-200 (2001)
Merkel, E.A., Gerami, P.: Malignant melanoma of sun-protected sites: a review of clinical, histological, and molecular features. Lab. Invest. 97, 630-635 (2017)

Mujoo, K., Sharin, V.G., Martin, E., Choi, B.K., Sloan, C., Nikonoff, L.E., Kots, A.Y., Murad, F.: Role of soluble guanylyl cyclase-cyclic GMP signaling in tumor cell proliferation. Nitric Oxide 22, 43-50 (2010)

Neubert, J., Schatz, A., Briegleb, W., Bromeis, B., Linke-Hommes, A., Rahmann, H., Slenzka, K., Horn, E.: Early development in aquatic vertebrates in near weightlessness during the D-2 Mission STATEX project. Adv. Space Res. 17, 275-279 (1996)

Park, H.Y., Gilchrest, B.A.: Signaling pathways mediating melanogenesis. Cell Mol. Biol. 45, 919-930 (1999)

Potter, L.R., Abbey-Hosch, S., Dickey, D.M.: Natriuretic peptides, their receptors, and cyclic guanosine monophosphate-dependent signaling functions. Endocr. Rev. 27, 47-72 (2006)

Romero-Graillet, C., Aberdam, E., Biagoli, N., Massabni, W., Ortonne, J.P., Ballotti, R.: Ultraviolet B radiation acts through the nitric oxide and cGMP signal transduction pathway to stimulate melanogenesis in human melanocytes. J. Biol. Chem. 271, 28052-28056 (1996)

Rossler, A., Noskov, V., Laszlo, Z., Polyakow, V.V., HinghoferSzalkay, H.G.: Permanent depression of plasma cGMP during long-term space flight. Physiol. Res. 50, 83-90 (2001)

Sager, G.: Cyclic GMP transporters. Neurochem. Int. 45, 865-873 (2004)

Sample, A., He, Y.Y.: Mechanisms and prevention of UV-induced melanoma. Photodermatol. Photoimmunol. Photomed. 292, 1478614795 (2017)

Sasaki, M., Horikoshi, T., Uchiwa, H., Miyachi, Y.: Up-regulation of tyrosinase gene by nitric oxide in human melanocytes. Pigm. Cell Res. 13, 248-252 (2000)

Shi, Z.X., Rao, W., Wang, H., Wang, N.D., Si, J.W., Zhao, J., Li, J.C., Wang, Z.R.: Modeled microgravity suppressed invasion and migration of human glioblastoma U87 cells through downregulating store-operated calcium entry. Biochem. Biophys. Res. Commun. 457, 378-384 (2015)

Stieber, C., Ivanova, K., Block, I., Gerzer, R.: Hypergravity modulates cyclic GMP efflux in nitric oxide-stimulated human melanocytic cells. J. Gravit. Physiol. 12, 251-252 (2005)

Taylor, P.W.: Impact of space flight on bacterial virulence and antibiotic susceptibility. Infect. Drug Resist. 8, 249-262 (2015)

Thiel, C.S., Paulsen, K., Bradacs, G., Lust, K., Tauber, S., Dumrese, C., Hilliger, A., Schoppmann, K., Biskup, J., Golz, N., Sang, C., Ziegler, U., Grote, K.H., Zipp, F., Zhuang, F., Engelmann, F., Hemmersbach, R., Cogoli, A., Ullrich, O.: Rapid alterations of cell cycle control proteins in human $\mathrm{T}$ lymphocytes in microgravity. Cell Commun. Signal 10, 1 (2012)

Ullrich, O., Huber, K., Lang, K.: Signal transduction in cells of the immune system in microgravity. Cell Commun. Signal 6, 9 (2008)

Ulbrich, C., Pietsch, J., Grosse, J., Wehland, M., Schulz, H., Saar, K., Hubner, N., Hauslage, J., Hemmersbach, R., Braun, M., van Loon, J., Vagt, N., Egli, M., Richter, P., Einspanier, R., Sharbati, S., Baltz, T., Infanger, M., Ma, X., Grimm, D.: Differential gene regulation under altered gravity conditions in follicular thyroid cancer cells: relationship between the extracellular matrix and the cytoskeleton. Cell. Physiol. Biochem. 28, 185-198 (2011)

Van Muijen, G.N., Cornelissen, L.M., Jansen, C.F., Figdor, C.G., Johnson, J.P., Brocker, E.B., Ruiter, D.J.: Antigen expression of metastasizing and non-metastasizing human melanoma cells xenografted into nude mice. Clin. Exp. Metastasis 9, 259-272 (1991)

Wielinga, P.R., van der Heijden, I., Reid, G., Beijnen, J.H., Wijnholds, J., Borst, P.: Characterization of the MRP4- and MRP5-mediated transport of cyclic nucleotides from intact cells. J. Biol. Chem. 278, 17664-17671 (2003)

Zhao, Y., Schelvis, J.P., Babcock, G.T., Marletta, M.A.: Identification of histidine 105 in the beta1 subunit of soluble guanylate cyclase as the heme proximal ligand. Biochemistry 37, 4502-4509 (1998) 